\title{
Recovery of body composition improves long-term outcomes after lung volume reduction surgery for emphysema
}

\author{
D. Mineo, V. Ambrogi, V. Lauriola, E. Pompeo and T.C. Mineo
}

ABSTRACT: Nutritional status deteriorates along with progression of emphysema, with the decline of body composition correlating with risk of disease-related events. Lung volume reduction surgery (LVRS), by improving respiratory function and recovering body composition, may influence long-term disease-related morbidity and mortality when compared to respiratory rehabilitation (RR).

In this non-randomised study, 44 male patients with moderate-to-severe emphysema underwent LVRS, while 35 received RR. Respiratory parameters, body composition, number and time-tooccurrence of disease-related events were evaluated for 5 yrs.

After LVRS, respiratory and nutritional parameters had significantly greater and longer lasting improvements than after RR. Disease-related events occurred later and less frequently after surgery than after rehabilitation, with better morbidity and mortality survival curves $(p<0.01$ and $\mathrm{p}<0.03$, respectively). Body mass index $(\mathrm{BMI}) \geqslant 23 \mathrm{~kg} \cdot \mathrm{m}^{-2}, \mathrm{BODE}$ (BMI, airflow obstruction, dyspnoea, exercise capacity) index $\leqslant 2$ and fat-free mass index (FFMI) $\geqslant 16 \mathrm{~kg} \cdot \mathrm{m}^{-2}$ at $1 \mathrm{yr}$ were the best positive predictors of post-operative outcomes $(p<0.03, p<0.04$ and $p<0.005$, respectively). Reduction in residual volume at $\mathbf{3 6}$ months after surgery was significantly correlated with the increase of BMI $(\rho=-0.56, p=0.009)$ and FFMI $(\rho=-0.64, p=0.001)$.

LVRS significantly and durably improved respiratory function and body composition over RR. Relationships among residual volume, BMI, FFMI and disease-related events suggest that recovery in respiratory dynamics improves nutritional status, thus significantly reducing longterm disease-related morbidity and mortality.

KEYWORDS: Body composition, emphysema, lung volume reduction surgery, morbidity, mortality, respiratory rehabilitation

n emphysema, persistent inflammation, chron-

ic hypoxia, altered respiratory mechanics,

higher energy expenditure and steroid therapy are responsible for a deterioration of nutritional and clinical status, the so-called respiratory cachexia [1]. Body mass index (BMI) and body composition are severely affected, with a decline of fat mass (FM) but especially of fat-free mass (FFM), and inversely correlated with the severity of emphysema and clinical outcomes, thus increasing disease-related morbidity and mortality [2-5].

Lung volume reduction surgery (LVRS) in selected patients has been shown to be more effective in improving respiratory function and symptoms, exercise capacity and quality of life, than maximal medical therapy and respiratory rehabilitation (RR), with better long-term survival and post-operative amelioration of nutritional status, thus predicting both short- and long-term outcomes [6-11].
We hypothesised that LVRS, by restoring a more appropriate respiratory dynamics and function, could induce a significant and durable recovery in body composition that might improve longterm clinical outcomes by reducing diseaserelated morbidity and mortality when compared to RR.

The aims of this study were to analyse the change in body composition after LVRS, by dual-energy X-ray absorptiometry (DEXA), during a 5-yr follow-up, and to evaluate its influence on longterm disease-related morbidity and mortality.

\section{MATERIALS AND METHODS}

\section{Study design and populations}

This non-randomised study was conducted from July 1998, after approval by our ethics committee (Comitato Etico dell'Università di Roma Tor Vergata, Rome, Italy), until June 2003 and included

\section{AFFILIATIONS}

Division of Thoracic Surgery, School of Medicine, Tor Vergata University of Rome, Rome, Italy.

\section{CORRESPONDENCE}

D. Mineo

Division of Thoracic Surgery

School of Medicine

Tor Vergata University of Rome

Viale Oxford 81

00133 Rome

Italy

E-mail:d.mineo@med.uniroma2.it

Received:

Sept 082009

Accepted after revision:

Nov 182009 
intergroup (LVRS versus RR) and intragroup evaluations (baseline versus post-treatment). Written informed consent was obtained. 36 months after treatment patients were allowed to move to the other treatment arm and these were excluded from further statistical evaluations.

Indications for LVRS were previously reported [6-8]. Inclusion criteria required that patients were: clinically stable; performing mild physical activity; were nonsmokeres for $\geqslant 3$ months;

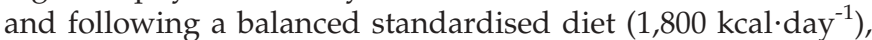
at enrolment and throughout the study period. Exclusion criteria ruled out patients who were oxygen dependent, had undergone RR in the last year, had cardio-cerebrovascular abnormalities, were suffering other chronic diseases or who were receiving any therapy interfering with nutritional status or metabolism.

79 male patients with moderate-to-severe emphysema at timed spirometry and with heterogeneous, symmetric, mainly upperlobe-located emphysema at high-resolution computed tomography and/or perfusion scan were selected for LVRS. Of these, 44 patients (mean age $63.2 \pm 5.6 \mathrm{yrs}$ ) underwent onestage bilateral LVRS through video-thoracoscopic approach, while the remaining $35(62.5 \pm 5.1$ yrs $)$ refused the intervention for personal reasons (psychological refusal of surgery, fear of peri-operative complications or lack of confidence in the procedure) and underwent standardised RR every 6 months during the first year and once a year thereafter [8] (fig. 1).

At enrollment, all patients were receiving oral and inhaled steroids plus inhaled $\beta_{2}$-agonists. The daily dosage was calculated from each 3-month medical visit during follow-up.

\section{Respiratory evaluation}

Arterial blood gases, plethismography, timed spirometry and single breath diffusing capacity of the lung for carbon monoxide $(D \mathrm{~L}, \mathrm{CO})$ were measured. Respiratory muscles strength was assessed by maximal inspiratory pressure (MIP) at residual volume and exercise tolerance by 6-min walking test. Dyspnoea index was rated by the Medical Research Council score ( 1 =best, $3=$ worst), and quality of life by the St George's Respiratory Questionnaire ( 0 =best, $100=$ worst). BODE index (BMI, airflow obstruction, dyspnoea, exercise capacity) was also calculated $(0=$ best, $10=$ worst $)[8,12]$.

\section{Nutritional evaluation}

Body weight and BMI were routinely evaluated. Total body and regional tissue composition of FM and FFM were measured by DEXA in absolute and percentage values using a total body scanner (QDR-2000; Hologic, Waltham, MA, USA), as previously described [13]. FM and FFM (kg) were adjusted for body surface area by division for height (m) squared, obtaining the related indexes FMI and FFMI [14].

\section{Energetic metabolism evaluation}

Total oxygen uptake $\left(V^{\prime} \mathrm{O}_{2}\right)$, assumed as summation of metabolic $V^{\prime} \mathrm{O}_{2}$ and respiratory muscles $V^{\prime} \mathrm{O}_{2}$, was measured at rest using a calorimetric chamber with an indirect method. Resting energy expenditure (REE), respiratory quotient and energy substrata oxidation, expressed as absolute values and percentage of utilisation, were derived from standardised formulas. Respiratory muscles $V^{\prime} \mathrm{O}_{2}$ was calculated as the

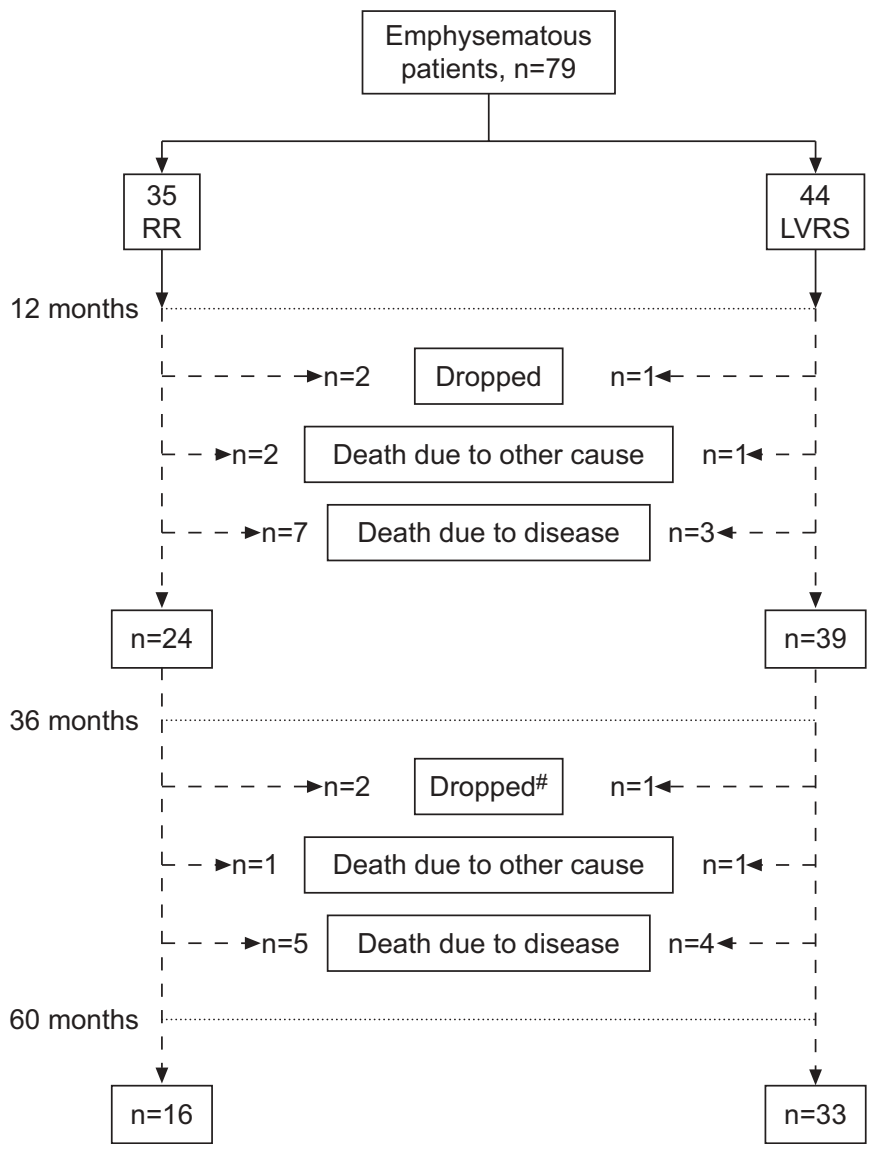

FIGURE 1. Algorithm of patient's treatment and follow-up. RR: respiratory rehabilitation; LVRS: lung volume reduction surgery. ${ }^{*}$ : patients who crossed to the other study arm and were excluded from further statistical evaluations.

proportion of $V^{\prime} \mathrm{O}_{2}$ of respiratory muscles $\left(V^{\prime} \mathrm{O}_{2}, \mathrm{Resp} \%\right)$ compared to total $V^{\prime} \mathrm{O}_{2}$, using measured and predicted REE values. Measured REE and $V^{\prime} \mathrm{O}_{2}$ were then corrected for FFM [15].

\section{Disease-related events and survival evaluations}

Number and time-to-occurrence of each disease-related morbidity event and causes of death were recorded after diagnosis using standardised criteria (International Classification of Diseases 9th revision), including: infective pneumonia; respiratory failure; cor pulmonale; cardiovascular accidents (i.e. arrhythmia, myocardial infarction or stroke); pulmonary embolism; and lung cancer. Patients were excluded from the study if they died from unrelated diseases or due to sudden events, or if they left the study for any reason.

\section{Statistical evaluation}

Non-parametric tests were used and significance was defined as $\mathrm{p}<0.05$ (SPSS version 14.0; SPSS Inc., Chicago, IL, USA). Time-to-first event of disease-related morbidity and mortality was evaluated by Kaplan-Meier curves (starting point was the day of the operation and end-point was the day of first morbidity or death), and factors influencing post-operative events were assessed by dichotomising for mean values of each continuous variable at $1 \mathrm{yr}$ (log-rank test). This timeframe was chosen as the proper period in which to expect the maximal post-treatment improvement in body composition. Correlation 
analysis between post-operative (after LVRS) percentage changes of the main respiratory and nutritional variables and regression analysis between post-treatment (after LVRS and RR) values of the main respiratory and nutritional variables and the number of disease-related morbidity events were performed.

\section{RESULTS}

At baseline, no statistical difference was found between LVRS and RR groups in demographics, clinical history, respiratory and nutritional parameters, energetic metabolism and medical therapy (fig. 2).

\section{Respiratory evaluation}

After LVRS all parameters significantly improved at $1 \mathrm{yr}$ and then slowly declined, while after RR, despite a mild improvement in some respiratory parameters at $1 \mathrm{yr}$, all variables shortly returned to baseline values. In the LVRS group, the BODE index significantly decreased at $1 \mathrm{yr}$ and then increased (from $3.8 \pm 1.7$ to $1.9 \pm 1.4(\mathrm{p}<0.01)$, to $3.0 \pm 1.4(\mathrm{p}<0.05)$ and to $3.4 \pm 1.3$ at 12,36 and 60 months, respectively), while in RR, after an improvement at $1 \mathrm{yr}$, it worsened (from $3.8 \pm 1.9$ to $2.4 \pm 1.5(\mathrm{p}<0.05)$, to $3.3 \pm 2.0$ and to $3.7 \pm 1.7$ at 12,36 and 60 months, respectively) (fig. 2).

\section{Nutritional evaluation}

After LVRS, BMI, FFM and FM, and the relative indexes FFMI and FMI, significantly increased at 12 months, remained stable at 36 months and slightly declined at 60 months, while after $\mathrm{RR}$, despite a mild improvement at $1 \mathrm{yr}$, they progressively reduced (fig. 2, table 1 ).

Considering BMI $<21 \mathrm{~kg} \cdot \mathrm{m}^{-2}$ and FFMI $<16 \mathrm{~kg} \cdot \mathrm{m}^{-2}$ as cutoffs for cachexia (or undernourishment) in emphysema [14], at baseline, 14 (32\%) out of 44 LVRS patients and 11 (31\%) out of 35 RR patients were undernourished for BMI, while 28 $(63 \%)$ and $22(63 \%)$, respectively, were undernourished for FFMI. At $1 \mathrm{yr}$, nine LVRS patients regained a proper BMI, with five $(11 \%)$ out of 44 persisting undernourished, while only three RR patients regained a proper BMI, with eight (23\%) out of 35 remaining cachetic. In the LVRS group, seven patients recovered a correct FFMI, with 21 (47\%) remaining undernourished, while in the RR group, only two patients recovered a correct FFMI, with 20 (57\%) remaining cachetic. At 3 yrs, three LVRS patients returned undernourished for BMI with a total of 5 undernourished patients out of 39 available for follow-up (13\%) compared to five RR patients out of a total of seven out of 24 undernourished patients available for follow-up (29\%). Three LVRS patients returned cachetic for FFMI (19 out of 39; 49\%) compared to three RR patients (16 out of $24 ; 67 \%$ ). At 5 yrs, two LVRS patients reverted to being undernourished (five out of 33; 15\%) compared to all the RR patients. Four LVRS patients returned to being cachetic for FFMI (17 out of $33 ; 52 \%$ ) compared to all the RR patients.

Regional tissue composition showed a significant and greater increment of FM at the trunk 12 months after LVRS $(0.8 \pm$ $0.1 \mathrm{~kg})$, which reduced at 36 and 60 months $(0.5 \pm 0.1 \mathrm{~kg}$ and $0.4 \pm 0.05 \mathrm{~kg}$, respectively). FFM showed a significant and greater increment in lower limbs $(1.1 \pm 0.3 \mathrm{~kg})$ at 12 months which persisted at 36 and 60 months $(1.0 \pm 0.2 \mathrm{~kg}$ and
$0.8 \pm 0.1 \mathrm{~kg}$, respectively). No changes in regional tissue composition were found after RR (table 1).

\section{Energetic metabolism evaluation}

30 LVRS patients and 28 RR patients were evaluated. After LVRS, $V^{\prime} \mathrm{O}_{2}, \mathrm{Resp} \%$ with $V^{\prime} \mathrm{O}_{2}$, Resp\% and REE, both corrected for FFM, were significantly reduced at 12 months but increased thereafter. At 1 yr post-surgery, substrata utilisation shifted from prevalent-lipid (from $79 \pm 12 \mathrm{~g} \cdot 24 \mathrm{~h}^{-1}$ to $50 \pm 8 \mathrm{~g} \cdot 24 \mathrm{~h}^{-1}$, $\mathrm{p}<0.001$ ) to prevalent-carbohydrate oxidation (from $100 \pm$ $1 \mathrm{~g} \cdot 24 \mathrm{~h}^{-1}$ to $143 \pm 16 \mathrm{~g} \cdot 24 \mathrm{~h}^{-1}, \mathrm{p}<0.001$ ), with proteins sparing (from $97 \pm 9 \mathrm{~g} \cdot 24 \mathrm{~h}^{-1}$ to $83 \pm 9 \mathrm{~g} \cdot 24 \mathrm{~h}^{-1}, \mathrm{p}<0.01$ ). Afterwards, this trend reversed, with reduction of carbohydrate utilisation $\left(126 \pm 12 \mathrm{~g} \cdot 24 \mathrm{~h}^{-1}(\mathrm{p}<0.01)\right.$ at 36 months and $112 \pm 11 \mathrm{~g} \cdot 24 \mathrm{~h}^{-1}$ $(\mathrm{p}<0.05)$ at 60 months $)$, and increment of lipids $\left(58 \pm 6 \mathrm{~g} \cdot 24 \mathrm{~h}^{-1}\right.$ $(\mathrm{p}<0.001)$ and $62 \pm 9 \mathrm{~g} \cdot 24 \mathrm{~h}^{-1}(\mathrm{p}<0.001)$, respectively $)$ and protein oxidation $\left(88 \pm 9 \mathrm{~g} \cdot 24 \mathrm{~h}^{-1}(\mathrm{p}<0.05)\right.$ and $92 \pm 10 \mathrm{~g} \cdot 24 \mathrm{~h}^{-1}$, respectively). Respiratory quotient increased at 12 months (from $0.79 \pm 0.2$ to $0.82 \pm 0.2, \mathrm{p}<0.05$ ), remained stable at 36 months but was reduced at 60 months $(0.81 \pm 0.3$ and $0.80 \pm 0.2$, respectively). After $\mathrm{RR}, V^{\prime} \mathrm{O}_{2}, \mathrm{Resp} \%, V^{\prime} \mathrm{O}_{2}$ and $\mathrm{REE}$ showed a gradual worsening, with persistent prevalent-lipid substrate metabolism and reduced respiratory quotient (fig. 2).

\section{Steroid therapy evaluation}

At baseline, the LVRS and RR groups were closely matched for oral steroid dosage (methylprednisolone: $10.5 \pm 1.4 \mathrm{mg} \cdot \mathrm{day}^{-1}$ and $10.4 \pm 1.6 \mathrm{mg} \cdot \mathrm{day}^{-1}$, respectively) (fig. 2).

After LVRS, 21 out of 44 patients discontinued oral steroids at $1 \mathrm{yr}$ (discontinuing: baseline $10.4 \pm 1.4 \mathrm{mg} \cdot$ day $^{-1}$; post-treatment $100 \%$ reduction; $\mathrm{p}<0.0001$ ), while the remaining 23 patients significantly reduced their dose (continuing: baseline $10.5 \pm$ $1.4 \mathrm{mg} \cdot$ day $^{-1}$; post-treatment $7.0 \pm 0.9 \mathrm{mg} \cdot$ day $^{-1}, 31.8 \%$ reduction; $\mathrm{p}<0.001)$. By 3 yrs, all discontinuing patients restarted oral steroids but at a lower dose than at baseline $\left(7.2 \pm 1.1 \mathrm{mg} \cdot \mathrm{day}^{-1}\right.$, $30.7 \%$ reduction; $\mathrm{p}<0.001$ ), which did not significantly differ from that of the continuing patients $\left(7.9 \pm 1.4 \mathrm{mg} \cdot \mathrm{day}^{-1}, 24.5 \%\right.$ reduction; $\mathrm{p}<0.001)$. By 5 yrs, all operated patients were receiving oral steroids, still at lower dose than baseline $(8.3 \pm$ $1.3 \mathrm{mg} \cdot$ day $^{-1}, 20.2 \%$ reduction; $\mathrm{p}<0.01$ ).

After RR none of the patients discontinued oral steroids, although a significant dose reduction was achieved at $1 \mathrm{yr}$ (post-treatment $7.3 \pm 0.8 \mathrm{mg} \cdot$ day $^{-1}, 29.2 \%$ reduction; $\mathrm{p}<0.001$ ), which did not significantly differ from that of the LVRS patients continuing oral steroids. During follow-up, a progressive increase in oral steroid dose occurred from 3 yrs $\left(8.1 \pm 2.5 \mathrm{mg} \cdot \mathrm{day}^{-1}, 16.7 \%\right.$ reduction; $\mathrm{p}<0.01)$ to $5 \mathrm{yrs}\left(8.9 \pm 2.8 \mathrm{mg} \cdot \mathrm{day}^{-1}, 13.6 \%\right.$ reduction; $\left.\mathrm{p}<0.05\right)$, which did not significantly differ from that of the LVRS patients at both time-points.

At baseline, the dose of inhaled steroids and $\beta_{2}$-agonists was similar in the LVRS and RR groups and remained substantially unchanged for the whole study period: beclometasone $1.3 \pm 0.3 \mathrm{mg} \cdot$ day $^{-1}$ or budesonide $600 \pm 52 \mu \mathrm{g} \cdot$ day $^{-1}$; salbutamol $355 \pm 40 \mu \mathrm{g} \cdot$ day $^{-1}$ or formeterol $38 \pm 9 \mu \mathrm{g} \cdot$ day $^{-1}$.

No statistical difference was found at baseline among the two LVRS subsets (discontinuing and continuing) and the RR group, either in oral steroid dose or respiratory and nutritional parameters (data not shown). 
a)

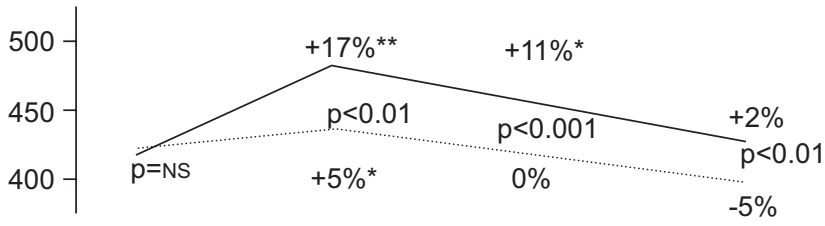

b)

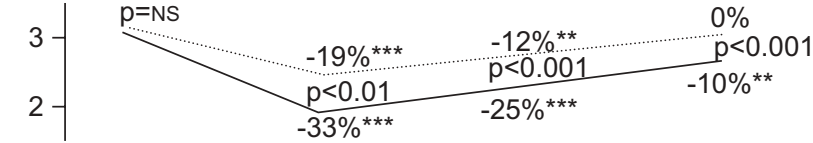

c)

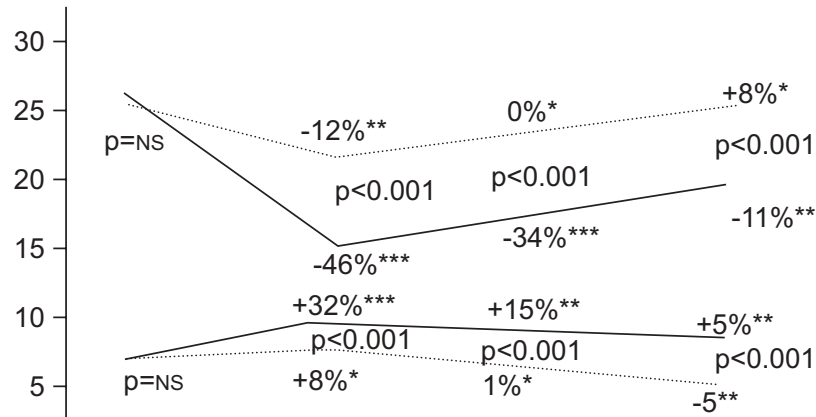

d)

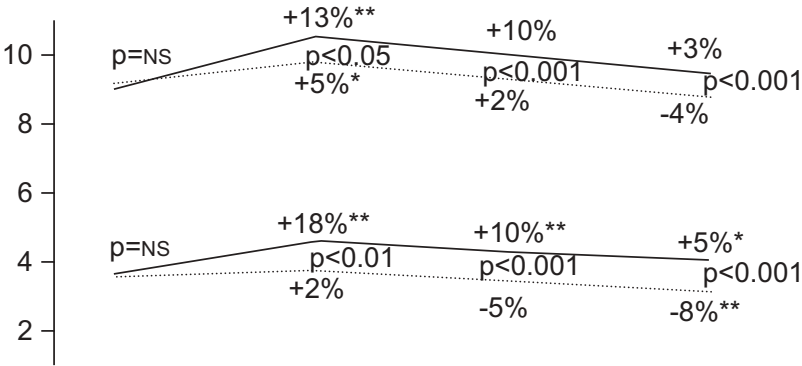

e)

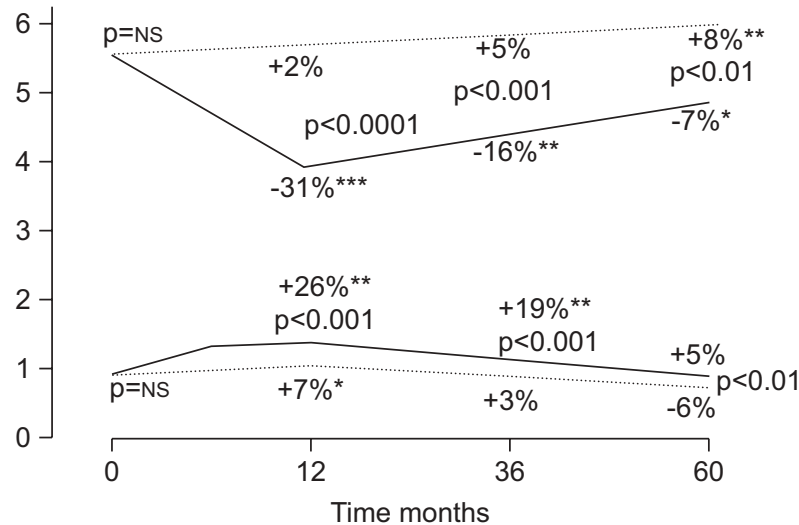

f)

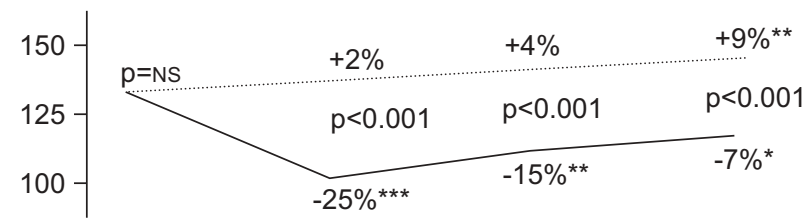

g)

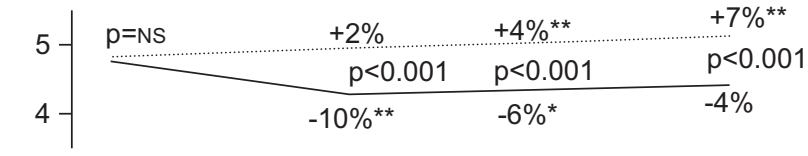

h)

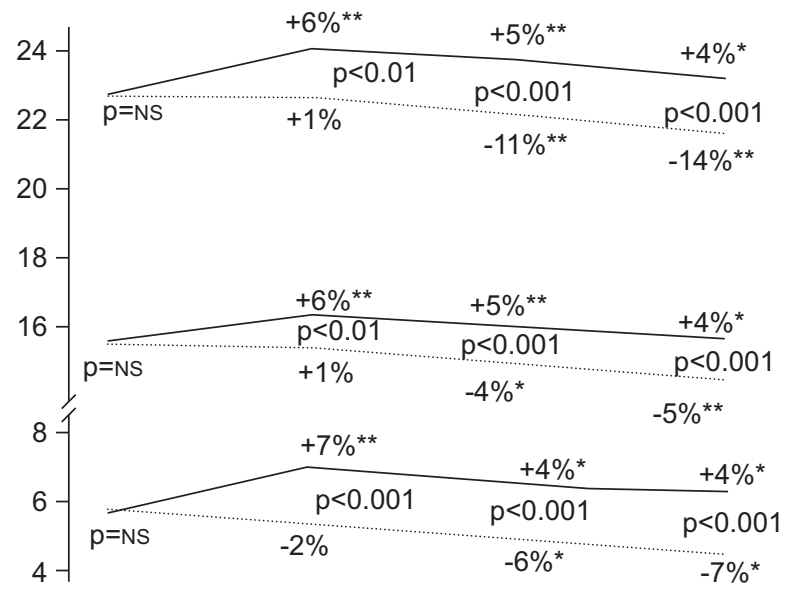

i)

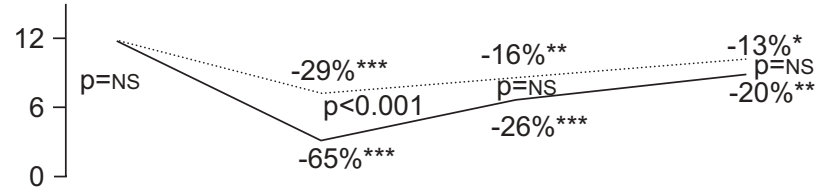

j)

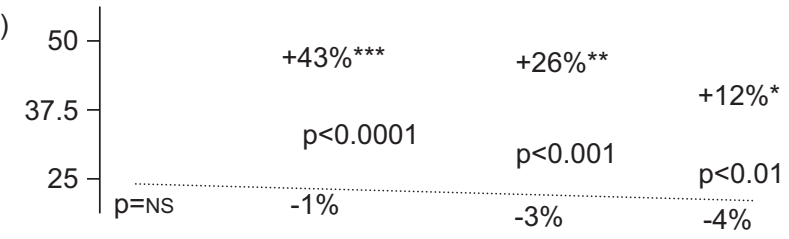

k)

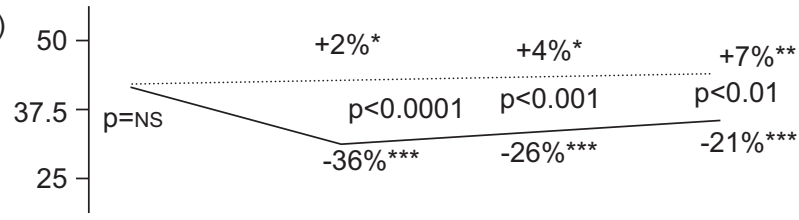

l)

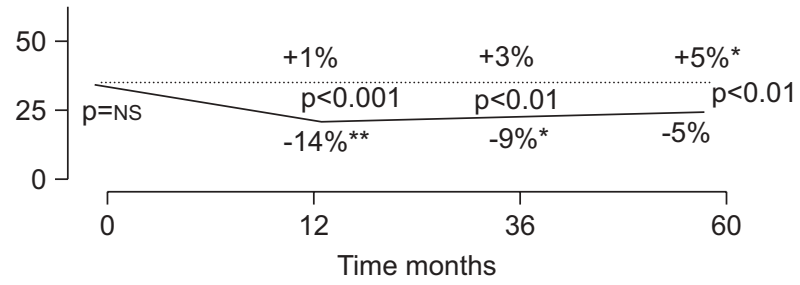

FIGURE 2. Mean percentage changes from baseline of main respiratory and nutritional parameters in the lung volume reduction surgery ( $\longrightarrow$ ) and respiratory rehabilitation (….) groups. a) 6-min walk test $(\mathrm{m})$, b) Medical Research council dyspnoea index, c) St George's Respiratory Questionnaire (\%) and maximal inspiratory pressure ( $\mathrm{kPa}$ ) (top and bottom, respectively), d) arterial oxygen tension ( $\mathrm{kPa}$ ) and diffusing capacity of the lung for carbon monoxide ( $\mathrm{mmol}^{\circ} \mathrm{kPa}^{-1} \cdot \mathrm{min}^{-1}$ ) (top and bottom, respectively), e) residual volume $(\mathrm{L})$ and forced expiratory volume in $1 \mathrm{~s}(\mathrm{~L})$ (top and bottom, respectively), f) resting energy expenditure/fat-free mass $\left.\left(\mathrm{kJ} \cdot \mathrm{kg}^{-1} \cdot 24 \mathrm{~h}^{-1}\right), \mathrm{g}\right)$ oxygen uptake/fat-free mass $\left.\left(\mathrm{mL} \cdot \mathrm{kg}^{-1} \cdot \mathrm{min}^{-1}\right), \mathrm{h}\right)$ body mass index $\left(\mathrm{kg} \cdot \mathrm{m}^{-2}\right)$, fat-free mass index $\left(\mathrm{kg} \cdot \mathrm{m}^{-2}\right)$ and FMl $\left(\mathrm{kg} \cdot \mathrm{m}^{-2}\right)($ top to bottom, respectively), i) methylprednisolone $\left.\left(\mathrm{mg}^{\mathrm{day}}{ }^{-1}\right), \mathrm{j}\right)$ carbohydrate oxidation (\%), k) lipid oxidation (\%) and I) protein oxidation (\%). NS: nonsignificant. ${ }^{*}: \mathrm{p} \leqslant 0.05 ;{ }^{*}$ : $\mathrm{p} \leqslant 0.01$; $\star * *: p \leqslant 0.001$ 
TABLE 1 Body composition in lung volume reduction surgery (LVRS) and respiratory rehabilitation (RR) groups

\begin{tabular}{|c|c|c|c|c|c|c|c|c|}
\hline \multirow[t]{2}{*}{ Measurements } & \multicolumn{4}{|c|}{ Fat-free mass } & \multicolumn{4}{|c|}{ Fat mass } \\
\hline & Baseline $\mathbf{g}$ & 12 month & 36 month & 60 month & Baseline $\mathbf{g}$ & 12 month & 36 month & 60 month \\
\hline \multicolumn{9}{|l|}{ Upper limbs } \\
\hline LVRS & $5800 \pm 270$ & $+4.1^{*}$ & +3.8 & +3.5 & $2560 \pm 145$ & $+4.6^{*}$ & $+4.2^{\star}$ & $+4.0^{*}$ \\
\hline $\mathrm{RR}$ & $5731 \pm 284$ & +0.7 & -2.2 & -2.3 & $2572 \pm 138$ & -2.1 & $-5.4^{*}$ & $-5.7^{\star}$ \\
\hline LVRS & $26256 \pm 2310$ & +3.7 & +3.5 & +3.2 & $8470 \pm 1230$ & $+9.7^{\star \star}$ & $+6.2^{\star \star}$ & $+5.2^{*}$ \\
\hline $\mathrm{RR}$ & $26123 \pm 1957$ & +0.2 & -4.6 & -4.7 & $8485 \pm 1245$ & -1.3 & $-6.1^{*}$ & $-6.4^{*}$ \\
\hline$p$-value & 0.91 & 0.05 & 0.02 & 0.02 & 0.91 & 0.007 & 0.001 & 0.001 \\
\hline \multicolumn{9}{|l|}{ Lower limbs } \\
\hline LVRS & $15620 \pm 1540$ & $+7.4^{\star \star}$ & $+7.1^{\star \star}$ & $+5.1^{*}$ & $6630 \pm 346$ & +3.9 & +3.1 & $+4.0^{\star}$ \\
\hline $\mathrm{RR}$ & $15590 \pm 1348$ & +1.4 & -2.3 & -2.5 & $6644 \pm 233$ & -2.3 & $-5.8^{*}$ & $-5.9^{*}$ \\
\hline $\mathrm{p}$-value & 0.81 & 0.03 & 0.006 & 0.01 & 0.92 & 0.001 & 0.001 & 0.001 \\
\hline
\end{tabular}

At 1 yr post-treatment, the LVRS patients discontinuing oral steroids showed the most significant improvements in the studied parameters. The LVRS patients continuing oral steroids experienced significant ameliorations compared with the RR patients, despite comparable dosage, as previously shown $[13,15]$; this observation persisted throughout the study period.

\section{Disease-related events and survival curve evaluations}

No patient died peri-operatively or in the first year posttreatment. During follow-up, two deaths due to other causes occurred in the LVRS group (prostate cancer $n=1$ and acute hepatitis $n=1$ ) and three deaths occurred in the RR group (colon cancer $n=1$, brain tumour $n=1$, car accident $n=1$ ), while two patients dropped out of the study in the LVRS group (residence change $n=1$, underwent $R R n=1$ ) and four patients dropped out in the RR group (lost to follow-up $n=2$, underwent LVRS n=2) (fig. 1).

Disease-related morbidity events occurred in fewer patients, with less frequency and longer median time-to-first event in the LVRS group compared to the RR group. Disease-related deaths arose less frequently and with longer median time-todeath in the LVRS group in comparison to the RR group (table 2).

Survival curves showed significant difference between the LVRS and RR groups for disease-related first-event of morbidity and mortality. The best positive predictors of postoperative outcomes were BMI $\geqslant 23 \mathrm{~kg} \cdot \mathrm{m}^{-2}(\mathrm{p}<0.03)$, BODE index $\leqslant 2(p<0.04)$ and FFMI $\geqslant 16 \mathrm{~kg} \cdot \mathrm{m}^{-2}(\mathrm{p}<0.005)$ at $1 \mathrm{yr}$. When dichotomising LVRS survival curves for these cut-offs, the operated patients significantly diverged for disease-related mortality and morbidity, with those beyond such limits having outcomes similar to the RR group (fig. 3).
According to these findings, at baseline 28 (63\%) out of 44 LVRS patients and $15(43 \%)$ out of 35 RR patients had a BMI $\geqslant 23 \mathrm{~kg} \cdot \mathrm{m}^{-2}$. In addition, four $(9 \%)$ LVRS and four $(11 \%) \mathrm{RR}$ patients had a BODE index $\leqslant 2$. At $1 \mathrm{yr}$, seven LVRS patients reached this BMI cut-off, with a total of 28 patients out of 44 at this limit $(63 \%)$, while only four out of $19(54 \%)$ RR patients achieved this BMI cut-off, with a total of 19 (54\%) out of 35 patients at this limit. 20 LVRS patients achieved this BODE index cut-off with a total of 24 (54\%) out of 44 patients, whereas only 13 RR patients achieved the BODE cut-off out of a total of $17(49 \%)$ out of 35 patients. At 3 yrs, 25 (64\%) out of 39 LVRS patients were available at follow-up, compared to only five (21\%) out of 24 RR patients available at follow-up. 19 $(49 \%)$ out of 39 patients maintained the targeted BODE index compared to only nine (38\%) out 39 RR patients. At 5 yrs, 11 (33\%) out of 33 LVRS patients maintained the BMI cut-off compared to no RR patients. Nine $(27 \%)$ out of 33 LVRS patients preserved the BODE index cut-off compared to two $(12 \%)$ out of 16 RR patients.

\section{Correlation and regression analysis}

Correlation analysis in the LVRS group showed that respiratory improvements were positively correlated with improvements in nutritrional status and energy metabolism, as previoulsyreported $[13,15]$. Ameliorations of forced expiratory volume in $1 \mathrm{~s}, D \mathrm{~L}, \mathrm{CO}$ and residual volume significantly correlated to increments of BMI and FFMI, and to decreases of REE corrected for FFM up to 36 months. Afterwards, such correlations disappeared, mainly due to the decline in respiratory function (table 3 ).

Regression analysis showed a significant relationship only between BMI and FFMI at 1 yr post-treatment and the number of disease-related morbidity events during follow-up (fig. 4). 
TABLE 2 Disease-related morbidity and mortality events in lung volume reduction surgery (LVRS) and respiratory rehabilitation (RR) groups

\begin{tabular}{|c|c|c|c|c|c|}
\hline \multirow[t]{2}{*}{ Measurements } & \multicolumn{3}{|c|}{ Disease-related morbidity } & \multicolumn{2}{|c|}{ Disease-related mortality } \\
\hline & Patients $\mathbf{n}$ & Events $\mathrm{n}$ & $\begin{array}{l}\text { Median time to first event } \\
\text { occurrence months }\end{array}$ & Patients n & $\begin{array}{l}\text { Median time to death } \\
\text { occurrence months }\end{array}$ \\
\hline \multicolumn{6}{|l|}{ LVRS $^{\#}$} \\
\hline Infective pneumonia & 9 & 13 & 7 & 1 & 22 \\
\hline Cardiovascular accidents & 6 & 8 & 13 & 2 & 25 \\
\hline Pulmonary embolism & 2 & 2 & 21 & & \\
\hline Lung cancer & 3 & 3 & 32 & 2 & 49 \\
\hline Total & $20^{+}$ & 34 & 11 & 7 & 22 \\
\hline \multicolumn{6}{|l|}{$\mathbf{R R}^{*}$} \\
\hline Infective pneumonia & 13 & 20 & 5 & 3 & 11 \\
\hline Lung cancer & 3 & 3 & 30 & 2 & 47 \\
\hline Total & $28^{+}$ & 50 & 8 & 12 & 14 \\
\hline Intergroup analysis on total values & $<0.01$ & $<0.001$ & $<0.05$ & $<0.01$ & $<0.001$ \\
\hline
\end{tabular}

\#: $n=44 ; \bullet: n=35 ;+$ : patients with at least one event.

None of the respiratory parameters reached statistical significance (data not shown).

\section{DISCUSSION}

Respiratory cachexia is present in $\geqslant 40 \%$ of patients with moderate-to-severe emphysema and body composition is deeply affected, with reduced FFM and FM. High prevalence of muscle tissue in the upper body is also present, mainly due to the overload of respiratory muscles with decreased walking activity $[1,3,4,16]$.

BMI is inversely correlated with the severity and prognosis of emphysema. FFMI appears to have an even stronger indirect correlation with the degree of airflow obstruction and the incidence of disease-related events and risk of death. The BODE index has shown to be a more accurate predictor of mortality and hospitalisation than functional respiratory parameters or BMI alone [2, 4, 5, 9-12, 14, 16-18].

LVRS significantly ameliorates nutritional status, energy expenditure and metabolism when compared to maximal medical and rehabilitation therapy, despite continuing oral steroids. BMI and BODE index also improve after surgery, correlating with post-operative outcomes. Reduction of residual volume and breathing overload, together with an increase of gas-exchange capacity and oxygen levels, seem to correlate with such post-operative improvements [6-10, 13, 15, 19-27].

In this 5-yr follow-up study, LVRS was the only treatment capable of providing a significant improvement of nutritional status, more durably than RR. Post-operative amelioration in body composition persisted significantly with time, while respiratory parameters progressively approximated to pre-operative values. Substrate utilisation and respiratory quotient showed a prolonged normalisation, reflecting a restoration of metabolism and energy expenditure, despite both breathing workload and pulmonary function starting to deteriorate. FFM and FM were significantly increased, in particular the FFM at lower limbs and FM at the trunk, with a redistribution pattern supporting the improvement of respiratory function and physical activity. Rates of cachexia, by standard BMI and FFMI cut-offs, considerably reduced after LVRS when compared to RR.

Only LVRS permitted the suspension of oral steroids, although partly and temporarily. Despite oral steroids restart or continuation at a lower dosage than baseline, more significant and prolonged improvements were observed after LVRS when compared to RR, even when a similar dose was administered. This finding elucidates the role of surgery per se in restoring body composition and energetic metabolism, eventually influencing disease-related morbidity and mortality.

After LVRS, disease-related morbidity and mortality significantly reduced in the number of affected patients and number of events, delayed the time-to occurrence and showed better long-term clinical outcomes than the RR group. The LVRS group seemed to be relatively more susceptible to cardiovascular accidents and lung cancer, while the RR group appeared to be more prone to respiratory and cardiac complications and failures.

$\mathrm{BMI} \geqslant 23 \mathrm{~kg} \cdot \mathrm{m}^{-2}, \mathrm{FFMI} \geqslant 16 \mathrm{~kg} \cdot \mathrm{m}^{-2}$ and BODE index $\leqslant 2$ at $1-\mathrm{yr}$ were the best cut-offs to predict a significant reduction of morbidity and mortality after surgery. LVRS patients not achieving such improvements showed significantly worse 

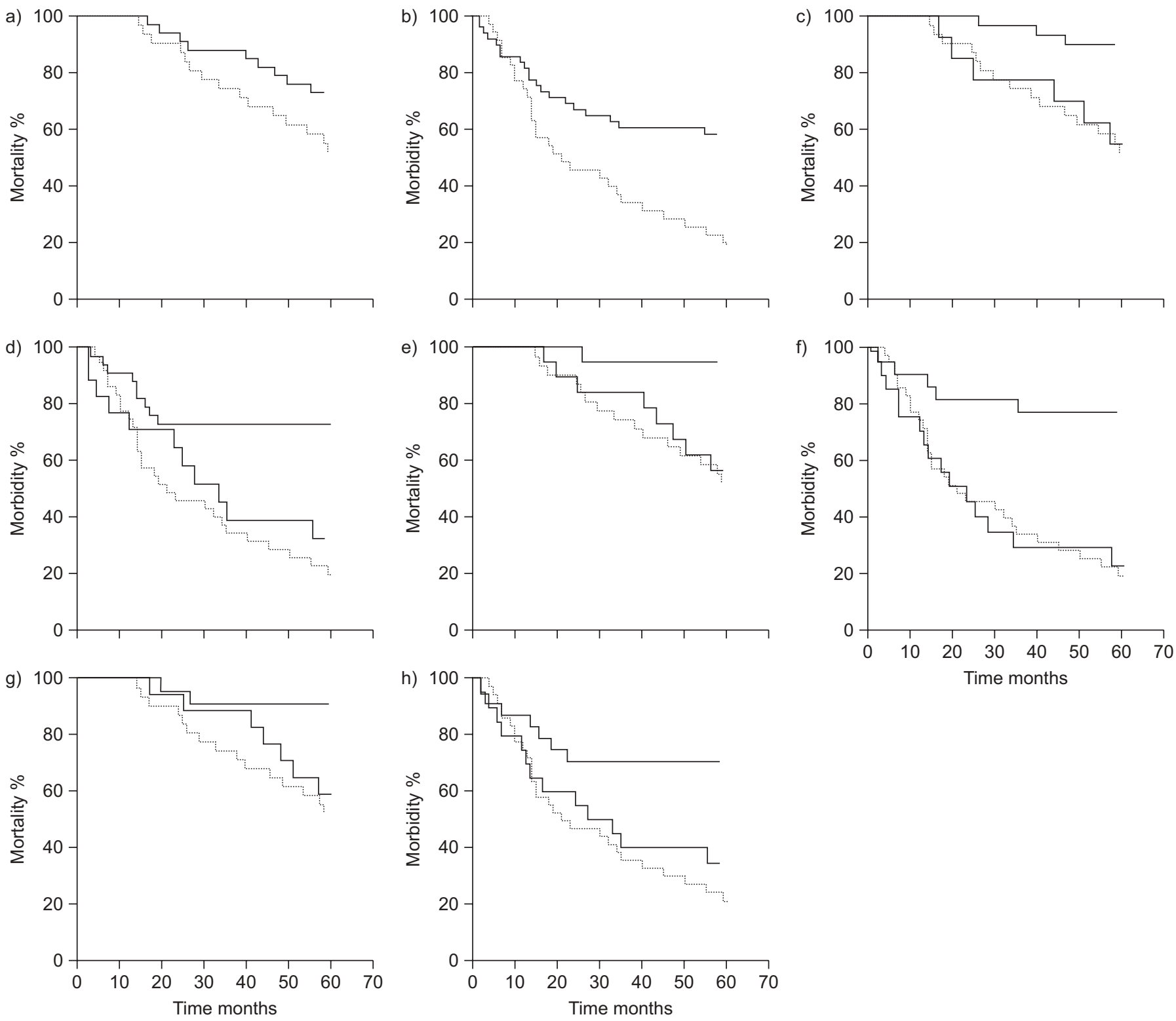

FIGURE 3. Kaplan-Meier curves for time-to-first-event of disease-related morbidity ( $a, c, e, g)$ and mortality (b, $d, f, h)$ in the lung volume reduction surgery (LVRS) ( - ) and respiratory rehabilitation (RR) (….....) groups. a, b) Cumulative: a) $\mathrm{p}<0.03, \mathrm{~b}$ ) $\mathrm{p}<0.01 . \mathrm{c}$, d) Body mass index (BMI) (upper line BMI $\geqslant 23 \mathrm{~kg} \cdot \mathrm{m}^{-2}$, lower line $\mathrm{BMI}$ $\left.<23 \mathrm{~kg} \cdot \mathrm{m}^{-2}\right)(p<0.03)$. e, f) Fat-free mass index (FFMl) (upper line FFMI $\geqslant 16$, lower line FFMle $\left.<16\right)(p<0.005)$. g, h) BODE (BMl, airway obstruction, dyspnoea, exercise capacity) index: (upper line BODE index $\leqslant 2$, lower line BODE index $>2)(p<0.04)$. The cut-off values were calculated at 1 yr post-treatment.

survival curves, similar to those of the RR group. FFMI showed to be a more accurate indicator than BMI for respiratory cachexia and disease-related events, outlining the importance of recovering muscle tissue content to improve respiratory function and general health status. The BODE index was less predictive long term, probably due to a progressive deterioration of the pulmonary parameters that largely contribute to its calculation. Rates of patient recovery for proper nutritional status, by achieving such selected cut-offs, were greater after surgery than rehabilitation, probably explaining the better clinical outcomes.

Correlation analysis confirmed the strict relationship between lung function and nutritional status, outlining the influence of the surgical restoration of respiratory dynamics and oxygen availability to tissues on reducing energy expenditure and recovering body composition. Regression analysis showed that disease-related morbidity events occurred more frequently after RR than after LVRS, in association with a persistent poor nutritional status, especially a lower FFMI.

No major or sustained improvements were seen after RR in respiratory function and body composition and, despite a transitory amelioration of some parameters at $1 \mathrm{yr}$, both variables continued to deteriorate with time. Disease-related morbidity and mortality events occurred more frequently and earlier in the RR group than in the LVRS group, and were associated with a worsening nutritional status. 
TABLE 3 Correlation analysis between post-operative percentage changes of respiratory and nutritional variables

FEV $1 \%$ change

$\rho=0.61 ; p=0.004$
$\rho=0.49 ; p=0.02$
$\rho=0.30 ; p=0.09$
$\rho=0.52 ; p=0.01$
$\rho=0.62 ; p=0.003$
$\rho=0.35 ; p=0.07$
$\rho=0.60 ; p=0.005$
$\rho=0.51 ; p=0.01$
$\rho=0.34 ; p=0.08$

DL,CO \% change

$\rho=0.45 ; p=0.01$
$\rho=0.39 ; p=0.04$
$\rho=0.33 ; p=0.08$
$\rho=0.63 ; p=0.001$
$\rho=0.61 ; p=0.009$
$\rho=0.46 ; p=0.01$
$\rho=0.53 ; p=0.007$
$\rho=0.42 ; p=0.03$
$\rho=0.36 ; p=0.07$

Residual volume \% change

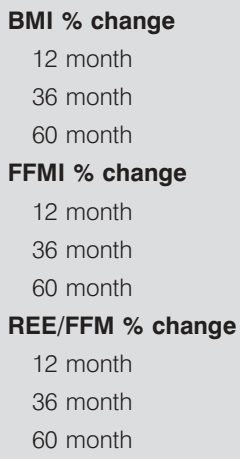

FEV1: forced expiratory volume in 1 expenditure; FFM: fat-free mass.
We hypothesised that LVRS, by reducing lung residual volume as well as by regaining pulmonary microcirculation and airspace, restores respiratory dynamics and function and increases oxygen tissue availability. Such changes reduce breathing workload and energy expenditure, reverse the hyper/catabolic metabolism and normalise the hormonal profile, with recovery in body weight and composition, especially muscle tissue. Overall, these events could explain the durable improvement in respiratory function, exercise performance and quality of life as well as the reduction of long-term disease-related morbidity and mortality observed after lung surgery [27-30].

Limitations include the non-randomised nature of the trial, the relatively small sample size with only male subjects, the lack of assessment of inflammatory mediators and glycolipidic hormones, and the effect of smoking cessation.

In conclusion, LVRS significantly and steadily improves nutritional status compared with RR, with amelioration of body composition, reduction of energy expenditure, and more physiological substrata utilisation. FFM and FM showed postoperative regional tissue redistribution, as shown by improved metabolism and exercise capacity. Relationships among respiratory and nutritional variables, mainly residual volume and FFMI, with disease-related events suggest that postoperative recovery in respiratory mechanics and function may improve nutritional status and energetic metabolism, significantly reducing long-term morbidity and mortality.

In this selected group of emphysematous patients, with relevant airway obstruction (predicted forced expiratory volume $34.6 \pm 11.4 \%$ ) and undernourishment (BMI $22.8 \pm 1.4 \mathrm{~kg} \cdot \mathrm{m}^{-2}$ ), LVRS is a relatively low-risk procedure, the only treatment able to modify the natural history of emphysema by temporarily reversing its severity and reducing the occurrence of complications. Recovery in nutritional status may define two opposite patterns of response to surgery with significantly different longterm outcomes, with FFMI being able to predict the postoperative evolution of emphysema more than BMI or BODE
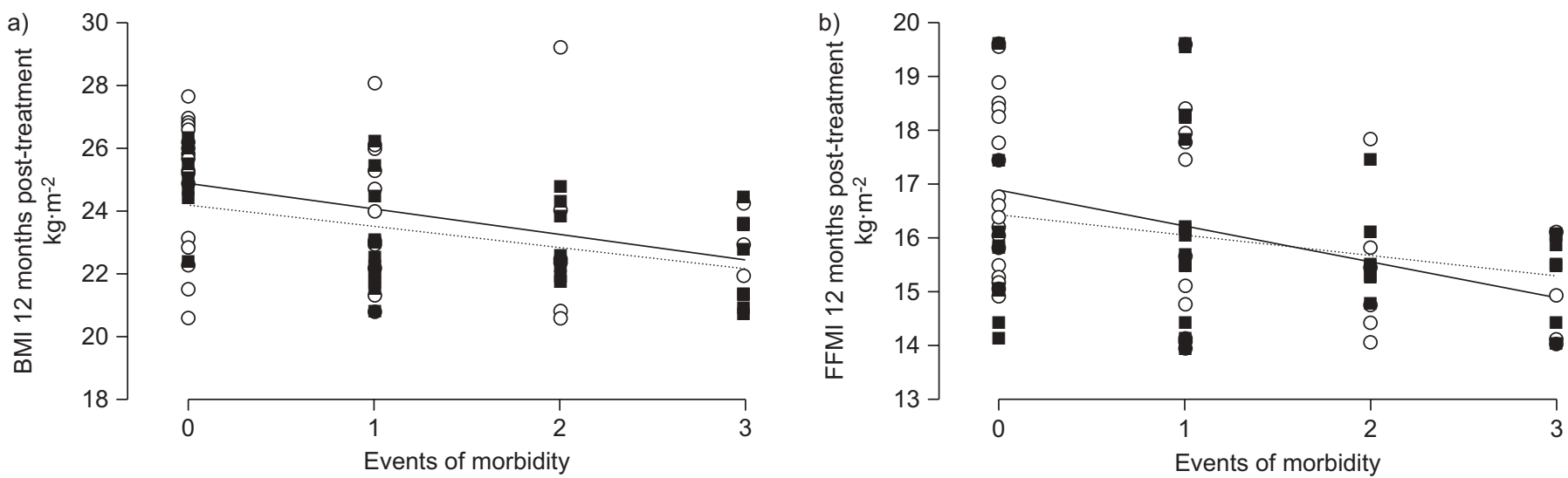

FIGURE 4. Regression analysis of the lung volume reduction surgery (LVRS) $(-; \bigcirc)$ and respiratory rehabilitation (RR) $(\cdots \cdots \cdot \ldots ; \mathbf{\square})$ groups between values of a) body mass index (BMI) and b) fat-free mass index (FFMI) at 1 yr post-treatment and the number of disease-related morbidity events. a) LVRS: $R^{2}=0.12, p<0.01 ; R R: R^{2}=0.18$, $p<0.01$. b) LVRS: $R^{2}=0.15, p<0.01 ; R R: R^{2}=0.06, p<0.05$ 
index. Assessment of body composition by the safe and economical DEXA should be recommended in post-operative monitoring and management to guide adequate nutritional and medical support.

\section{SUPPORT STATEMENT}

D. Mineo performed the study within the Research Fellowship Program "Tecnologie e Terapie Avanzate in Chirurgia" awarded by Tor Vergata University of Rome (Rome, Italy). This research was supported by Ministero per l'Università e la Ricerca Scientifica e Tecnologica (Rome) (grants 9906274194-06 and 2001061191-001), Consigilio Nazionale delle Ricerche (grant CU0100935CT26 2002), Tor Vergata University of Rome, Centro di Eccellenza (2001).

\section{STATEMENT OF INTEREST}

None declared.

\section{ACKNOWLEDGEMENTS}

We deeply thank J. Wilkes for the linguistic revision of the manuscript.

\section{REFERENCES}

1 Wagner PD. Possible mechanisms underlying the development of cachexia in COPD. Eur Respir J 2008; 31: 492-501.

2 Landbo C, Prescott E, Lange P, et al. Prognostic value of nutritional status in chronic obstructive pulmonary disease. Am J Respir Crit Care Med 1999; 160: 1856-1861.

3 Remels AH, Gosker HR, van der Velden J, et al. Systemic inflammation and skeletal muscle dysfunction in chronic obstructive pulmonary disease: state of the art and novel insights in regulation of muscle plasticity. Clin Chest Med 2007; 28: 537-552.

4 Fabbri LM, Luppi F, Beghé B, et al. Complex chronic comorbidities of COPD. Eur Respir J 2008; 31: 204-212.

5 Sin DD, Anthonisen NR, Soriano JB, et al. Mortality in COPD: role of comorbidities. Eur Respir J. 2006; 28: 1245-1257.

6 Cooper JD, Patterson GA. Lung-volume reduction surgery for severe emphysema. Chest Surg Clin North Am 1995; 5: 815-831.

7 National Emphysema Treatment Trial Research Group. A randomized trial comparing lung-volume-reduction surgery with medical therapy for severe emphysema. $N$ Engl J Med 2003; 348: 2059-2073.

8 Pompeo E, Marino M, Nofroni I, et al. Reduction pneumoplasty versus respiratory rehabilitation in severe emphysema: a prospective randomized study. Ann Thorac Surg 2000; 70: 948-953.

9 Naunheim KS, Wood DE, Mohsenifar Z, et al. Long-term followup of patients receiving lung-volume-reduction surgery versus medical therapy for severe emphysema. National Emphysema Treatment Trial Research Group. Ann Thorac Surg 2006; 82: 431-443.

10 Appleton S, Adams R, Porter S, et al. Sustained improvements in dyspnea and pulmonary function 3 to 5 years after lung volume reduction surgery. Chest 2003; 123: 1838-1846.

11 Imfeld S, Bloch KE, Weder W, et al. The BODE index after lung volume reduction surgery correlates with survival. Chest 2006; 129: 873-878.

12 Celli BR, Cote CG, Marin JM, et al. The body-mass index, airflow obstruction, dyspnea, and exercise capacity index in chronic obstructive pulmonary disease. N Engl J Med 2004; 350: 1005-1012.
13 Mineo TC, Ambrogi V, Mineo D, et al. Bone mineral density improvement after lung volume reduction surgery for severe emphysema. Chest 2005; 127: 1960-1966.

14 Schols AM, Broekhuizen R, Weling-Scheepers CA, et al. Body composition and mortality in chronic obstructive pulmonary disease. Am J Clin Nutr 2005; 82: 53-59.

15 Mineo TC, Pompeo E, Mineo D, et al. Resting energy expenditure and metabolic changes after lung volume reduction surgery for emphysema. Ann Thorac Surg 2006; 82: 1205-1211.

16 Schols AM. Pulmonary cachexia. Int J Cardiol 2002; 85: 101-110.

17 Ischaki E, Papatheodorou G, Gaki E, et al. Body mass and fat-free mass indices in COPD: relation with variables expressing disease severity. Chest 2007; 132: 164-169.

18 Martinez FJ, Han MK, Andrei AC, et al. Longitudinal change in the BODE index predicts mortality in severe emphysema. Am J Respir Crit Care Med 2008; 178: 491-499.

19 Lederer DJ, Thomashow BM, Ginsburg ME, et al. Lung-volume reduction surgery for pulmonary emphysema: improvement in body mass index, airflow obstruction, dyspnea, and exercise capacity index after 1 year. J Thorac Cardiovasc Surg 2007; 133: 1434-1438.

20 Pompeo E, Mineo TC. Two-year improvement in multidimensional body mass index, airflow obstruction, dyspnea, and exercise capacity index after nonresectional lung volume reduction surgery in awake patients. Ann Thorac Surg 2007; 84: 1862-1869.

21 Mineo D, Ambrogi V, Frasca L, et al. Effects of lung volume reduction surgery for emphysema on glycolipidic hormones. Chest 2008; 134: 30-37.

22 Meyers BF, Yusen RD, Guthrie TJ, et al. Results of lung volume reduction surgery in patients meeting a national emphysema treatment trial high-risk criterion. J Thorac Cardiovasc Surg 2004; 127: 829-835.

23 Criner GJ, Cordova FC, Furukawa S, et al. Prospective randomized trial comparing bilateral lung volume reduction surgery to pulmonary rehabilitation in severe chronic obstructive pulmonary disease. Am J Respir Crit Care Med 1999; 160: 2018-2027.

24 McKeough ZJ, Alison JA, Bayfield, et al. Reduction in resting energy expenditure following lung volume reduction surgery in subjects with chronic obstructive pulmonary disease. Chron Respir Dis 2004; 1: 197-202.

25 Mazolewski P, Turner JF, Baker M, et al. The impact of nutritional status on the outcome of lung volume reduction surgery. A prospective study. Chest 1999; 116: 693-696.

26 Vaughan P, Oey IF, Steiner MC, et al. A prospective analysis of the inter-relationship between lung volume reduction surgery and body mass index. Eur J Cardiothorac Surg 2007; 32: 839-842.

27 Geddes D, Davies M, Koyama H, et al. Effect of lung-volumereduction surgery in patients with severe emphysema. $N$ Engl J Med 2000; 343: 239-245.

28 Becker MD, Berkmen YM, Austin JH, et al. Lung volumes before and after lung volume reduction surgery: quantitative $\mathrm{CT}$ analysis. Am J Respir Crit Care Med 1998; 157: 1593-1599.

29 Sciurba FC, Rogers RM, Keenan RJ, et al. Improvement in pulmonary function and elastic recoil after lung-reduction surgery for diffuse emphysema. N Engl J Med 1996; 334: 1095-1099.

30 Criner G, Cordova FC, Leyenson V, et al. Effect of lung volume reduction surgery on diaphragm strength. Am J Respir Crit Care Med 1998; 157: 1578-1585. 